\title{
Factors affecting the organization of accounting work in manufacturing enterprises located in VSIP1 industrial park in Binh Duong province
}

\author{
Huynh Xuan Hiep, Nguyen Dong Phuong, \\ Nguyen Chi Cong, and Hoang Dinh Dung \\ Faculty of Finance \& Accounting \\ Hochiminh City University of Food Industry \\ xuanhieptckthufi@gmail.com
}

\begin{abstract}
Through the mixed and descriptive analysis research methods, the authors study the impact of factors on accounting work in manufacturing enterprises located in VSIP1 Industrial Park in Binh Duong province. The research results show that 6 factors affect the accounting work in these enterprises, arranged from high to low, including requirements for IT application, internal control system, professional qualities of accountants, company size, legal regulations, demand for accounting information. From the research results, the authors offer solutions for accounting work in these organizations.

Index Terms-organization of accounting work, internal control, IT application, legal regulations, manufacturing enterprises.
\end{abstract}

\section{INTRODUCTION}

$\mathrm{I}$ $\mathrm{N}$ THE current context of international integration, Vietnamese enterprises and foreign ones in VSIP1 industrial park not only compete fiercely with domestic companies but also with foreign companies that are strong in terms of capital, brand name, and management skills. Therefore, to survive and develop, businesses must be autonomous in their production and business activities, maximizing profits and finding reasonable directions. One of the solutions is to constantly innovate, improve efficiency and perfect the management apparatus, improve facilities, invest in the application of scientific advances, and improve the qualifications of the management team, employees, ... of which, the important things serving the basis for implementation is accounting information. Therefore, if enterprises want to develop sustainably, they need to organize the accounting work and operate effectively.

\section{Literature Review}

The research [1] measures the success of an information system by the following factors: system quality, information quality, quality of service, user satisfaction, net benefits. This is a model newly developed based on the author's previous research model.

The research [2] shows that the factors that determine the quality of accounting information when applying IFRS include: legal and political systems, accounting standards, and the presentation of financial statements. In which, the legal and political system is the factor affecting accounting quality in different directions. It can directly affect the quality of information or indirectly affect the quality of accounting in- formation through accounting standards and the presentation of financial statements.

The research [3] has identified and measured the factors affecting the organization of the accounting work in small and medium enterprises in Tra Vinh city. The research results show that 8 factors affect the organization of the accounting work in small and medium enterprises in Tra Vinh city. These factors are listed herein from the most influential ones to the least ones: financial and accounting services, users of accounting information, management requirements, internal control system, legal systems, sizes of enterprises, application of information technology (IT), owner's concern, and accounting human resources.

The research [4] presents the theoretical basis related to the organization of the accounting work in the food processing companies in Ho Chi Minh City, then describes and analyzes the current situation of organizing the accounting work in those companies. From there, the author proposes recommendations to improve the organization of accounting work in food processing companies.

In summary, with the literature review of domestic and foreign researches, it can be seen that there has not been any research that aims directly, fully, and systematically to the organization of accounting work in manufacturing companies in VSIP1 Industrial Park in Binh Duong province.

\section{Research Methods}

\section{A. Data and data collection methods}

Secondary data is collected through articles and researches done at home and abroad on the organization of accounting work in the enterprises, factors affecting the organization of accounting work in enterprises. Primary data is collected from $03 / 2020$ - 05/2020 by the survey questionnaires sent directly to the respondents. The contents of the questions are those variables used in the research model and using the Likert scale for the questionnaire: 1 - Totally disagree, 2 - Disagree, 3 - Neutral, 4 - Agree, 5 - Totally agree. Respondents are directors, deputy directors, heads/deputy heads of departments, and officials and employees working in manufacturing companies in VSIP1 industrial park of Binh Duong province.

To achieve the proposed sample size and ensure that the research results are representative of the overall population, 200 surveys were sent out. 6 surveys that were invalid be- 
cause they answered the same level for all questionnaires or lacked a lot of information out of the total 185 surveys collected. As a result, 180 valid surveys were used as data for the study. Data are entered, encrypted, cleaned, and analyzed through the SPSS. 20.

\section{B. Research hypothesis and research model}

In the study, the authors used the exploratory factor analysis (EFA) model to determine and test the relationship between factors (independent variables) affecting the quality of accounting information in commercial enterprises in Ho Chi Minh City (dependent variable).

\section{1) Legal regulations}

For enterprises in general and manufacturing companies in particular, organizing accounting work in these units to suit the unique characteristics of this type of business requires specific documents. Specific legal regulations on the contents of the organization of accounting work such as organizing the accounting apparatus appropriately, applying the system of vouchers, the system of accounting accounts so that it is reasonable and regulated. on methods, techniques for preparing and presenting financial statements,... The right legal environment will create favorable conditions for enterprises to develop business activities, but to do this, public organizations Effective accounting is not to be missed. Therefore, the establishment of a legal framework for the organization of accounting work in these enterprises is an urgent requirement.

Hypothesis H1 is given as Current legal regulations positively affect the organization of accounting work in manufacturing companies in VSIP1 industrial park of Binh Duong province.

\section{2) Internal control system}

Internal control systems are procedures used to achieve the organization's objectives. Two important goals in organizing accounting work are to ensure the safety of assets and ensure that accounting data is highly accurate and reliable. Evaluate the system of internal control to determine how it affects the accuracy of accounting information. An understanding of internal control is essential for any accountant who specializes in assessing how internal control affects the amount of work they are required to perform when conducting an audit. accuracy of accounting information. However, several enterprises today build an ineffective internal control system because the business owner hardly pays attention to the internal control system; lacks of understanding of the internal control system; not enough human resources to divide responsibilities; ... affecting the operational efficiency of the enterprise in general and the effectiveness of the organization of accounting work in particular.

Hypothesis H2 is given as Effective internal control systems positively affect the organization of accounting work in manufacturing companies in VSIP1 industrial park of Binh Duong province.

\section{3) Requirement for applications of IT}

In today's business activities, the quality of accounting organizations has a great influence on business performance. Therefore, a fast and strong accounting organization system, providing accurate and timely information, as a basis for leaders to make decisions quickly and effectively is ex- tremely necessary. Due to the diversity and complexity of business activities, accounting software has become the most effective and accurate support tool to help businesses process information quickly and safely, provide accounting reports. timely and effective accounting. The application of information technology in accounting work needs to be implemented effectively according to the investment in information technology, the application of technology in accounting activities needs to balance between the benefits that technology brings and costs incurred to obtain that benefit.

Hypothesis H3 is given as Requirement for applications of IT in accounting positively affect the organization of accounting work in manufacturing companies in VSIP1 industrial park of Binh Duong province.

4) Professional qualifications of accountants

The qualifications of accountants have a great influence on the organization of accounting work in enterprises. If the accounting staff is not professional and not highly qualified, it can affect the stages in the accounting work such as collecting incomplete information, reflecting inaccurate and untimely accounting information. providing inaccurate, dishonest, and objective information... In addition, if the accounting staff has low qualifications, it will also affect the organization of the accounting apparatus such as having to have many new employees to take over. do all the work of the accounting department, the accounting work is not efficient.

Hypothesis H4 is given as Professional qualifications of accountants positively affect the organization of accounting work in manufacturing companies in VSIP1 industrial park of Binh Duong province.

5) Demand for using accounting information

The need to use accounting information greatly affects the organization of accounting work in enterprises. The organization of accounting work in enterprises must meet the needs of business administrators. The accounting information needs of a business include financial accounting information and management accounting information. In principle, the provided management accounting information must comply with the accounting regime and per the Accounting Standards. Management accounting information is provided according to the needs of the internal use of the enterprise. Both financial accounting and management accounting meets the information needs of different subjects, but are related to each other in corporate governance activities and carry out procedures according to prescribed regimes.

Hypothesis H5 is given as: Demands for using accounting information positively affect the organization of accounting work in manufacturing companies in VSIP1 industrial park of Binh Duong province.

\section{6) Size of enterprise}

According to the research of Ismail (2009), the different size units, the organization of accounting work are also different, specifically according to this study, for small and medium-sized units, the organization requirements are also different. Accounting is certainly different from large enterprises.

To organize the accounting work in an enterprise, it is necessary to base on the scale of operation, the characteris- 
tics of the industry and the field of operation; The characteristics of production organization and management as well as the nature of the production process in the enterprise must be based on the policies and regimes promulgated by the State. Organizing accounting work per the operating situation of the business not only saves costs but also ensures the provision of fast, complete, and quality information with different management requirements.

Hypothesis H6 is given as Sizes of enterprises positively affect the organization of accounting work in manufacturing companies in VSIP1 industrial park of Binh Duong province.

\section{Data processing method}

Descriptive statistical techniques are used to describe the basic characteristics of the data collected from the surveys such as gender, experience, and qualifications of the respondents. On the other hand, data collected through quantitative steps are processed on SPSS. 20.

\section{Research Results}

\section{A. Verifying the quality of the scale}

Table 1: The Results of analyzing the Quality of the SCAle with Cronbach's Alpha coefficients

\begin{tabular}{|c|l|c|c|}
\hline No. & \multicolumn{1}{|c|}{ Variables } & $\begin{array}{c}\text { No of } \\
\text { items }\end{array}$ & Cronbach's \\
\hline \multicolumn{4}{|c|}{ Independent variables } \\
\hline 1 & $\begin{array}{l}\text { Requirement for applications of IT in } \\
\text { accounting }\end{array}$ & 4 & 0.885 \\
\hline 2 & $\begin{array}{l}\text { Professional qualifications of } \\
\text { accountants }\end{array}$ & 4 & 0.721 \\
\hline 3 & Legal regulations & 5 & 0.818 \\
\hline 4 & Internal control systems & 5 & 0.807 \\
\hline 5 & $\begin{array}{l}\text { Demands for using accounting } \\
\text { information }\end{array}$ & 4 & 0.842 \\
\hline 6 & Sizes of enterprises & 4 & 0.854 \\
\hline \multicolumn{4}{|c|}{ Dependent variables } \\
\hline 7 & $\begin{array}{l}\text { Organization of accounting work in } \\
\text { manufacturing companies in VSIP1 } \\
\text { industrial park of Binh Duong } \\
\text { province }\end{array}$ & 4 & 0.872 \\
\hline
\end{tabular}

Through testing the reliability of the scale of the observed variables in the research model, the observed variables all have Cronbach's Alpha coefficients greater than 0.6. This shows that the observed variables of the scales ensure reliability. Therefore, all observed variables are retained for EFA analysis.

Exploratory factor analysis (EFA) for independent variables

\section{B. Testing EFA conformity}

TABle 2: KMO AND Bartlett's test

\begin{tabular}{|c|c|c|}
\hline $\begin{array}{l}\text { KMO Measure of } \\
\text { Sampling Adequacy. }\end{array}$ & .793 & \multicolumn{1}{|c|}{} \\
\hline \multirow{3}{*}{ Bartlett's test } & Approx. & 2216.954 \\
& Chi-Square & 325 \\
& df & .000 \\
\cline { 2 - 3 } & Sig. & \\
\hline
\end{tabular}

We see that $\mathrm{KMO}=0.793$. It satisfies the condition 0.5 $<\mathrm{KMO}<1$, EFA is suitable for actual data.

\section{Testing the correlation between observed variables.}

Through Table 2, we see that Sig. $<0.01$. It means that observed variables have a linear correlation with representative factors.

\section{Testing the interpretation of observed variables for} the factors.

TABLE 3: VARIANCE

\begin{tabular}{|c|c|c|c|c|c|c|}
\hline \multirow{2}{*}{$\begin{array}{c}\text { Com- } \\
\text { ponent }\end{array}$} & \multicolumn{3}{|c|}{ Initial Eigenvalues } & \multicolumn{3}{c|}{ Extraction Sums of Squared } \\
\cline { 2 - 7 } & Total & $\begin{array}{c}\text { \% of } \\
\text { variance }\end{array}$ & $\begin{array}{c}\text { Cumu } \\
\text {-lative \% }\end{array}$ & Total & $\begin{array}{c}\text { \% of } \\
\text { variance }\end{array}$ & $\begin{array}{c}\text { Cumu- } \\
\text { lative \% }\end{array}$ \\
\hline 1 & 6.031 & 23.198 & 23.198 & 6.031 & 23.198 & 23.198 \\
\hline 2 & 3.087 & 11.874 & 35.071 & 3.087 & 11.874 & 35.071 \\
\hline 3 & 2.834 & 10.901 & 45.972 & 2.834 & 10.901 & 45.972 \\
\hline 4 & 1.990 & 7.654 & 53.626 & 1.990 & 7.654 & 53.626 \\
\hline 5 & 1.521 & 5.851 & 59.478 & 1.521 & 5.851 & 59.478 \\
\hline 6 & 1.377 & 5.297 & 64.775 & 1.377 & 5.297 & 64.775 \\
\hline
\end{tabular}

After calculating the fixed number of factors, we find out that the extracted variance of $64.775 \%>50 \%$, satisfying the requirement. With the Principal components extraction method and Varimax rotation, there are 6 factors extracted from the observed variables. This also means that the 6 extracted factors show the ability to explain $64.775 \%$ of the change of the dependent variable in the population.

E. Results of EFA:

TABle 4: Rotated COMPONENT MATRIX

\begin{tabular}{|c|c|c|c|c|c|c|}
\hline & \multicolumn{6}{|c|}{ Component } \\
\hline & 1 & 2 & 3 & 4 & 5 & 6 \\
\hline YCCN2 & .887 & & & & & \\
\hline YCCN1 & .872 & & & & & \\
\hline YCCN3 & .866 & & & & & \\
\hline YCCN4 & .814 & & & & & \\
\hline QDPL5 & & .764 & & & & \\
\hline QDPL2 & & .749 & & & & \\
\hline QDPL1 & & 681 & & & & \\
\hline QDPL3 & & 676 & & & & \\
\hline QDPL4 & & .668 & & & & \\
\hline QMDN4 & & & .833 & & & \\
\hline QMDN1 & & & .763 & & & \\
\hline QMDN2 & & & .747 & & & \\
\hline QMDN3 & & & .723 & & & \\
\hline KSNB4 & & & & .807 & & \\
\hline KSNB2 & & & & .806 & & \\
\hline KSNB3 & & & & .801 & & \\
\hline KSNB5 & & & & 677 & & \\
\hline KSNB1 & & & & .639 & & \\
\hline NCTT2 & & & & & .811 & \\
\hline NCTT1 & & & & & .809 & \\
\hline NCTT4 & & & & & .762 & \\
\hline NCTT3 & & & & & .707 & \\
\hline TDCM3 & & & & & & .749 \\
\hline TDCM2 & & & & & & .726 \\
\hline TDCM4 & & & & & & .697 \\
\hline TDCM1 & & & & & & .629 \\
\hline
\end{tabular}

The results of EFA showed that the variables were gathered into 6 groups. Factor loading of the variables is greater than 0.5 and the difference between the components of the same factor is greater than 0.3 . Then the groups of factors are collected into 6 groups with 26 observed variables.

\section{F. EFA analysis for the dependent variable}

The dependent variable "Organization of accounting work at manufacturing companies in VSIP1 industrial park in 
Binh Duong province" with 6 observed variables, the EFA shows that all conditions of exploratory factor analysis are met, $\mathrm{KMO}$ coefficient $=0.735>0.5$; Sig. $=0,000<0.05$; factor loading $>0.5$; and total variance is quite high $60,665 \%>$ $50 \%$ and satisfactory (Table 5).

TABle 5: KMO AND Bartlett's test

\begin{tabular}{|c|c|c|}
\hline \multicolumn{2}{|c|}{ KMO Measure of Sampling } & .735 \\
\hline Bdequacy & \\
\hline Bartlett's & Approx. Chi- & 209.28 \\
test & Square & 3 \\
& df & 6 \\
\cline { 2 - 3 } & Sig & .000 \\
\hline
\end{tabular}

Table 6: Variance

Total variance explained

\begin{tabular}{|c|c|c|c|c|c|c|}
\hline \multirow{2}{*}{$\begin{array}{c}\text { Comp } \\
\text { onent }\end{array}$} & \multicolumn{3}{|c|}{ Initial Eigenvalues } & \multicolumn{3}{c|}{ Extraction Sums of Squared } \\
\cline { 2 - 7 } & Total & $\begin{array}{c}\text { \%of of } \\
\text { var- } \\
\text { iance }\end{array}$ & $\begin{array}{c}\text { Cumul- } \\
\text { ative \% }\end{array}$ & Total & $\begin{array}{c}\text { \% of } \\
\text { var- } \\
\text { iance }\end{array}$ & $\begin{array}{c}\text { Cumul- } \\
\text { ative \% }\end{array}$ \\
\hline 1 & 2.427 & 60.665 & 60.665 & 2.427 & 60.665 & 60.665 \\
2 & .699 & 17.464 & 78.129 & & & \\
3 & .541 & 13.522 & 91.651 & & & \\
4 & .334 & 8.349 & 100.000 & & & \\
\hline
\end{tabular}

\section{G. Regression analysis}

Findings from previous research steps and the EFA analysis results show that the following factors on factors affect the organization of accounting work in manufacturing companies in VSIP1 industrial park of Binh Duong province: requirements for application of IT in accounting, internal control systems, professional qualifications of accountants, sizes of enterprises, legal regulations, demands for using accounting information.

The regression equation is written as follows:

CTKT $=0.360 \mathrm{YCCN}+0.258 \mathrm{TDCM}+0.219 \mathrm{QDPL}+$ $0.285 \mathrm{KSNB}+0.164 \mathrm{NCTT}+0.239 \mathrm{QMDN}$

Of which:

CTKT: Organization of accounting work in manufacturing companies in VSIP1 Industrial Park of Binh Duong province

QDPL: Legal regulations

KSNB: Internal control systems

YCCN: Requirements for application of IT in accounting

TDCM: Professional qualifications of the accountant

NCTT: Demand for using accounting information

QMDN: Sizes of enterprises

\section{H. Testing the suitability of the model}

Table 7: Testing the suitability of the Model

\begin{tabular}{|l|l|l|l|l|l|}
\hline Model & $\mathrm{R}$ & $\begin{array}{l}\mathrm{R} \\
\text { Square }\end{array}$ & $\begin{array}{l}\text { Adjusted } \\
\text { R Square }\end{array}$ & $\begin{array}{l}\text { Std. Error } \\
\text { of the Es- } \\
\text { timate }\end{array}$ & Durbin-Watson \\
\hline 1 & $.787^{\mathrm{a}}$ & .619 & .606 & .29859 & 1.945 \\
\hline
\end{tabular}

Research results show that the value of adjusted correlation coefficient $R^{2}$ is $0.606>0.5$. Therefore, this is a suitable model to be used to evaluate the relationship between the dependent variables and the independent variables.

The coefficient of the adjusted $R$ square $R^{2}$ is $0.606>0.5$. That means the built linear regression model is consistent with the $60.6 \%$ data. This shows that about $60.6 \%$ of the variation of the dependent variable is due to the impact of the independent variables, the rest is due to the error of other factors. Durbin Watson test $=1.945$, which is in the range allowed $1<\mathrm{D}<3$, so there is no correlation phenomenon of residues.

TABle 8: AnOva AnAlysis

ANOVA $^{\mathrm{a}}$

\begin{tabular}{|c|c|c|c|c|c|}
\hline Model & $\begin{array}{c}\text { Sum of } \\
\text { Squares }\end{array}$ & df & $\begin{array}{c}\text { Mean } \\
\text { Square }\end{array}$ & F & Sig. \\
\hline Regression & 25.061 & 6 & 4.177 & 46.848 & $.000^{\mathrm{b}}$ \\
Residual & 15.424 & 173 & .089 & & \\
Total & 40.484 & 179 & & & \\
\hline
\end{tabular}

TABle 9: Regression analysis

\begin{tabular}{|c|c|c|c|c|c|}
\hline \multirow{2}{*}{ Model } & \multicolumn{2}{|c|}{$\begin{array}{c}\text { Unstandardized } \\
\text { coefficient }\end{array}$} & $\begin{array}{c}\text { Standardized } \\
\text { coefficient }\end{array}$ & \multirow{2}{*}{$\mathrm{t}$} & Sig. \\
\cline { 2 - 4 } & $\mathrm{B}$ & $\begin{array}{c}\text { Std. } \\
\text { Error }\end{array}$ & Beta & & \\
\hline & -.163 & .208 & & -.781 & .436 \\
YCCN & .158 & .021 & .360 & 7.637 & .000 \\
TDCM & .213 & .044 & .258 & 4.848 & .000 \\
QDPL & .181 & .048 & .219 & 3.777 & .000 \\
KSNB & .199 & .033 & .285 & 6.000 & .000 \\
NCTT & .119 & .040 & .164 & 2.949 & .004 \\
QMDN & .179 & .044 & .239 & 4.045 & .000 \\
\hline
\end{tabular}

From the regression results table, we see that the Sig coefficient of 6 independent factors is less than 5\% and the magnification coefficient VIF is very low $(<2)$. This proves that the multicollinearity phenomenon does not occur with the independent variables.

Regression equation:

CTKT $=0.360 \mathrm{YCCN}+0.258 \mathrm{TDCM}+0.219 \mathrm{QDPL}+$ $0.285 \mathrm{KSNB}+0.164 \mathrm{NCTT}+0.239 \mathrm{QMDN}$

To compare the impact level of each independent factor for CTKT, we base on the standardized Beta coefficient. Accordingly, the larger the standardized Beta, the more strongly that factor affects the dependent variable. As can be seen in the regression equation, among the 6 factors that affect the CTKT, factor - "Requirements for application of IT in accounting" has the strongest influence on CTKT with Beta $=0.360$; factor - "Internal control systems" has the second strongest influence with Beta coefficient $=0.285$; factor - "Professional qualifications of the accountants" has the third strongest influence with the coefficient Beta $=0.258$; factor - "Sizes of enterprises" has the fourth-strongest influence with the coefficient Beta $=0.239$; factor - "Legal regulations" have the fifth strongest influence with Beta coefficient $=0.219$; and lastly, factor - "Demand for using accounting information" has the lowest impact with Beta coefficient $=0.164$. 


\section{Discussing Research Results}

According to the results, 6 factors affect the organization of accounting work at manufacturing companies in VSIP1 in Binh Duong province. Each factor is discussed below.

H1: The factor "Legal regulations" has a positive impact on the organization of accounting work in manufacturing companies in VSIP1 in Binh Duong province. Through Beta coefficient $=0.219$, legal regulations have a positive impact on the organization of accounting work at manufacturing companies in VSIP1 in Binh Duong province. Currently, the State has promulgated a legal system such as the Law on Accounting, a system of accounting standards, and an accounting regime to ensure a sufficient basis to help businesses across the country operate in a unified manner. Our country's economy is integrating more and more deeply with the world economy. Therefore, to help businesses develop well in the future, the State needs to issue new or additional accounting standards to be more consistent with international accounting standards.

H2: The factor "Internal control system" has a positive impact on the organization of accounting work in manufacturing companies in VSIP1 in Binh Duong province. Through the coefficient of Beta $=0.285$, the internal control system has a positive impact on the organization of accounting work at manufacturing companies in VSIP1 in Binh Duong province. An internal control system is an effective tool in checking, controlling, preventing, and detecting frauds and errors, preparing truthful financial statements, and ensuring the implementation of legal regimes. , comply with laws and regulations. Through the implementation of the above functions, internal control, on the one hand, contributes to ensuring the quality of the accounting work of companies, contributing to improving the quality of accounting work.

H3: The factor "Requirements for information technology application" has a positive impact on the organization of accounting work at manufacturing companies in VSIP1 in Binh Duong province. The application of information technology to accounting helps companies to perform accounting functions more efficiently and effectively by reducing the time and labor of manual recording and processing. Requirements on information technology application have the first effect on the organization of accounting work at manufacturing companies in VSIP1 in Binh Duong province through the Beta index $=0.360$. Thus, the more effective the application of information technology is, the more it will improve the organization of accounting work at manufacturing companies in VSIP1 in Binh Duong province.

H4: The factor "Professional qualification of accountants" has a positive impact on the organization of accounting work in manufacturing companies in VSIP1 in Binh Duong province. Through the Beta coefficient $=0.258$, the professional qualifications of accountants have a positive impact on the organization of accounting work at manufacturing companies in VSIP1 Binh Duong Industrial Park. Accountants have an important role in the quality of accounting work because they are directly involved in the organization and operation of accounting. At the same time, when accounting staff has high professional qualifications, they can advise and support the Board of Directors on what to do to create a quality accounting organization. Therefore, it is necessary to focus on improving the quality and professional qualifications of accounting staff.

H5: The factor "Demand for using accounting information" has a positive impact on the organization of accounting work in manufacturing companies in VSIP1 in Binh Duong province. Through the Beta coefficient $=0.164$, the demand for accounting information has a positive impact on the organization of accounting work at manufacturing companies in VSIP1 Binh Duong Industrial Park. The need to use accounting information is an indispensable condition for the establishment, maintenance, and improvement of the efficiency of the organization of accounting work at companies, to meet the increasing requirements of users. use information inside and outside the company.

H6: The factor "Enterprise size" has a positive impact on the organization of accounting work in manufacturing companies in VSIP1 in Binh Duong province. Through Beta coefficient $=0.239$, enterprise size has a positive impact on the organization of accounting work at manufacturing companies in VSIP1 Binh Duong Industrial Park. Each company with different sizes will organize accounting work in different ways.

\section{Conclusion And Policy Implications}

Based on the above model testing results, the authors give several recommendations to help improve the accounting organization in manufacturing companies in VSIP1 Industrial Park of Binh Duong province as follows:

\section{A. Requirements for application of IT in accounting}

Organizing the application of IT in accounting to improve accounting labor productivity and provide adequate and timely accounting information to serve the management requirements of manufacturing companies in VSIP1 industrial park of Binh Duong province.

One of the first requirements for the successful application of IT to accounting is human resources. Manufacturing companies need to improve and pay more attention to training and retraining employees who directly handle the accounting job. They must also make a long-term plan for the training of the successor teams and promote the application of IT to management in general and accounting in particular.

\section{B. Internal control system}

Internal control has an important effect in improving the quality of accounting information by minimizing errors and frauds. However, sufficiently organized control will significantly increase the companies' operation costs. Therefore, the authors believe that combining the accounting work with the internal control system is essential.

The accounting systems of manufacturing companies in Vietnam in general and in VSIP1 Industrial Park of Binh Duong province, in particular, have integrated some control procedures. However, these procedures are based on empirical or emotional nature. As a result, they have not achieved high efficiency. 


\section{Professional qualifications of the accountant}

As far as the companies are concerned, the authors would like to propose several solutions to improve the quality of human resources as follows:

+ Regularly organize training courses and refresher courses in the profession and IT for accountants, at the same time update policies and new regimes on accounting for the accounting team.

+ Accounting staff recruitment process: recruiting employees with professional qualifications and ethics

+ Building a positive working environment, creating harmonious and healthy labor relations; promptly solving internal conflicts when arising. Organizing collective activities to strengthen interpersonal bonding. Commendation, discipline must be applied to the right person, the right job, and at the right time.

\section{Sizes of business}

Based on the accounting regime promulgated by the state, manufacturing companies located in VSIP1 Industrial Park of Binh Duong province base on the specific characteristics of their business type to set up a suitable accounting process, especially the management accounting work, fully regulating the functions, tasks and specific responsibilities of each accounting department, each accountant in the accounting apparatus. For small companies, it is possible to put the parts together to make the accounting apparatus more compact. For companies with many facilities operating far away from head-office and obtaining qualified accountants, it is possible to choose a scattered accounting apparatus organization model or a combination model that is both concentrated and scattered.

\section{E. Legal provisions}

Vietnam's economy is in the process of deep integration with the world economy; policies, economic and financial regimes, and taxes have always been completed, supplemented, and revised. Consequently, the process of organizing the accounting work of manufacturing companies must promptly and fully grasp the current provisions of the policies and regimes on economic and financial management, taxation, and trade law. In the trend of economic integration, Vietnam must build a legal framework of accounting, espe- cially accounting standards to be consistent with other countries' practices, per international accounting standards and specific characteristics of Vietnam's economy in each period in line with a suitable roadmap.

In the process of drafting new accounting standards, it is necessary to absorb the opinions of accounting experts such as teaching experts at accounting training institutions, research institutes, and experts working in organizations, businesses. After the implementation period, it is necessary to review and evaluate for amendment and supplement.

\section{F. Demand for using accounting information}

In society, many people need to use the information provided by accountants such as business managers, outsiders who have direct financial interests in the business, and outsiders who have indirect financial interests in the business. Therefore, to meet the needs of using accounting information, companies need to understand the needs of specific information of each subject to properly organize the accounting work through the following solutions:

+ Hold meetings among departments and divisions to determine the need for information related to the financial situation that the subjects wishing to use accounting information are interested in.

+ Coordination between departments in providing information, selecting documents, and saving costs.

+ Develop a long-term plan in providing effective information to internal as well as stakeholders so that information users who are not accounting savvy can also grasp.

\section{REFERENCES}

[1] W. H. Delone and E. R. McLean, "The Delone and McLean Moddel of information system success: A ten-year update," Journal of Management Information System, vol. 19, no. Spring 2003, pp. 9-30, 2003.

[2] Rapina, "Factors influencing the quality of accounting information system and its implications on the quality of accounting information research," Journal of finance and accounting, vol. 5, no. 2, 2014. N. S. Soderstrom and K. J. Sun, "IRFS adoption and accounting quality: A review," European Accounting Review, vol. 16, no. 4, pp. 675-702, 2007.

[3] P. T. Huyen, "Analysis of factors affecting the accounting organization in small and medium enterprises in Tra Vinh city," Hochiminh city University of Technology, Hochiminh City, 2018.

[4] H. T. Thao, "Factors affecting the organization of accounting work at food processing companies in Hochiminh City," Hochiminh city University of Technology, Hochiminh City, 2016. 